\title{
Laffer Traps and Monetary Policy
}

\author{
Patrick A. Pintus
}

This article focuses on the interaction, in a stylized economy with flexible prices, of monetary and fiscal policy when both are active-active in the sense that how the policy instrument is set depends on the state of the economy. Fiscal policy finances a given stream of government expenditures through distortionary labor taxes, and it operates under a strict balanced-budget rule. If monetary policy is passive, the economy may occasionally switch, because of self-fulfilling expectations, from the neighborhood of a "Laffer trap" equilibrium to the saddle-path leading to the highwelfare steady state. In the low-welfare stationary state, output, investment, and consumption are low while the tax rate is correspondingly high. However, active monetary policy may, by following a rule such that the nominal interest rate responds positively to the state of the economy, push the economy toward the high-welfare equilibrium and rule out expectation-driven business cycles. (JEL E32, E63, H31)

Federal Reserve Bank of St. Louis Review, May/June 2008, 90(3, Part 1), pp. 165-74.

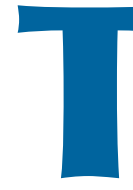

his article focuses on the interaction, in a stylized economy with flexible prices, of monetary and fiscal policy when both are active-active in the sense that the policy instrument depends on the state of the economy. The fiscal authority has to finance a given stream of government expenditures that is constant over time, reflecting some social needs to smooth out the production of public goods. To that end, the government levies distortionary taxes on labor income, but it does so under a strict rule that imposes a balanced budget in each period. As a consequence, the tax rate is countercyclical. Suppose that monetary policy is passive (e.g., that it keeps the rate of money growth constant over time). Then the economy possesses two steady states: one with a high tax rate (a "Laffer trap" equilibrium) and one with a low tax rate. The low stationary statewhere output, investment, and consumption are low-is Pareto-dominated by the high steady state and it is subject to expectation-driven business cycles. The main point of this article is to argue that switching to an active monetary policy may push the economy toward the high-welfare equilibrium and rule out expectation-driven business cycles. This happens, for instance, if the monetary authority follows a simple rule that stipulates how the nominal rate of interest responds to today's state of the economy.

This article obviously belongs to the vast literature that contrasts the effects of Friedman-type and Taylor-type monetary policy rules. It provides a simple example in which substituting a statecontingent policy for a passive rule may lead to better macroeconomic outcomes, in accord with the lesson one may draw from many articles in this area. However, in contrast with most of the recent research, the economy I focus on is not subject to the controversial sticky-price assump-

Patrick A. Pintus is a professor of economics at Université de la Méditerranée and GREQAM-IDEP; he was a visiting scholar at the Federal Reserve Bank of St. Louis at the time this article was written. The author thanks Costas Azariadis, Jim Bullard, Riccardo DiCecio, JeanMichel Grandmont, Robert Rasche, and Steve Williamson for useful discussions and suggestions.

(C) 2008, The Federal Reserve Bank of St. Louis. Articles may be reprinted, reproduced, published, distributed, displayed, and transmitted in their entirety if copyright notice, author name(s), and full citation are included. Abstracts, synopses, and other derivative works may be made only with prior written permission of the Federal Reserve Bank of St. Louis. 
tion. Therefore, the analysis suggests that the type of indeterminacy that is associated with passive policy (but eliminated by active policy) does not strictly depend on that assumption and may occur in a world where all prices are flexible.

I first show how a Laffer trap occurs when a given stream of government expenditures is financed by distortionary taxes and when the growth rate of the money supply is held constant over time. More precisely, I show that the economy has a low steady state, associated with a tax rate that is higher than the level that maximizes government revenues (which I call the Laffer maximal tax rate). It coexists with a high stationary state where consumption, investment, and output are higher. As a consequence, the higher stationary equilibrium is characterized by larger welfare and it Pareto-dominates the low steady state. Moreover, the high steady state is saddlepoint stable while the Laffer trap is locally indeterminate, so that sunspot equilibria occur near the low steady state. Most importantly, regime switching occurs when the economy occasionally jumps between the saddle-path (which converges monotonically toward the high steady state) and volatile paths around the Laffer trap. The main mechanism giving rise to indeterminacy is that households supply labor today according to their expectations about the inflation rate. More precisely, labor supply is higher (lower) when expected inflation is lower (higher). Consequently, waves of optimism or pessimism turn out to be self-confirming and the economy may experience excess volatility in the absence of any shocks to "fundamentals."

Second, I show that an active monetary policy may, by committing to a rule that links the nominal interest rate to output, push the economy toward the high-welfare equilibrium and rule out expectation-driven business cycles. One may think about this second type of policy as motivated by inflation targeting, which is designed to avoid large fluctuations of the inflation rate associated with indeterminacy. Alternatively, one may view this regime as originated by a max-min criterion that guides monetary policy and that aims at eliminating the "worst" equilibrium because it has both low welfare and excess volatility.
The analysis builds upon earlier work by introducing active fiscal and monetary policies in Woodford's (1986) framework. It complements the analysis of Leeper (1991), Schmitt-Grohé and Uribe (1997), and Antinolfi, Azariadis, and Bullard (2007) in the sense that I combine all elements of these studies in a simple monetary model with capital accumulation and credit constraints, in which I embed fiscal and monetary policies.

Perhaps the closest article is Leeper (1991). However, it differs along several dimensions: In particular, I do not impose a single budget constraint for the fiscal and monetary authorities. On the contrary, I assume that the government budget is balanced and that the central bank chooses its own policy rule. Fiscal policy consists of setting the tax rate on labor income while monetary policy decides on the nominal interest rate (and maybe lump-sum transfers). Also, unlike Leeper's (1991) model, my model incorporates physical capital accumulation and borrowing constraints.

As in Leeper (1991) and Schmitt-Grohé and Uribe (1997), I focus on policies that maintain a constant level of public spending over time, which may be justified by assuming that the government wishes to smooth out the production of public goods. Moreover, this hypothesis somewhat captures in a simple way the fact that public expenditures are much less volatile than output or factor income. Lane (2003; Table 1, p. 2669), for instance, reports some evidence suggesting that total government consumption has been acyclical in most Organisation for Economic Co-operation and Development (OECD) countries over the period 1960-98. What turns out to be a key assumption here is that public spending is predetermined when private agents make their own decisions, rather than when public spending is constant over time. Similar to Antinolfi, Azariadis, and Bullard (2007), some agents are subject to borrowing constraints. However, in the present article, credit-constrained households choose to hold outside money. Finally, Antinolfi, Azariadis, and Bullard (2007) abstract from both money and fiscal policy, in contrast with this article.

Unlike the conditions in Schmitt-Grohé and Uribe (1997), in the present article indeterminacy 
occurs for arbitrarily small values of government spending. In addition, the steady state is unique in Schmitt-Grohé and Uribe (1997) and is associated, when locally indeterminate, with a tax rate that is lower than the Laffer maximum. In contrast, my result shows that indeterminacy and expectation-driven business cycles arise because there exists a low, Pareto-dominated steady state, where the tax rate is higher than the Laffer maximum. The existence of such a Laffer trap calls for, in the setting of this article, a Pareto-improving, active monetary policy that cannot be implemented in the non-monetary economy of Schmitt-Grohé and Uribe (1997). However, much of the sensitivity analysis of these authors applies to this article, where, for instance, adding government debt does not alter the results as long as the balanced-budget requirement is maintained.

The monetary economy I focus on may be seen as an extension of Sargent and Wallace (1981), with capital accumulation and heterogenous agents. As in the analysis of these authors, the low steady state may be indeterminate. The model is also close to a commonly used framework in the public finance literature (see, e.g., Judd, 1985; Kemp, Van Long, and Shimomura, 1993; Alesina and Rodrik, 1994; and Lansing, 1999). This article adds to the public finance models by introducing monetary policy.

\section{A STYLIZED MONETARY ECONOMY WITH CONSTANT PUBLIC SPENDING}

In this section, I briefly present Woodford's (1986) model, to which I add government expenditures, distortionary labor taxes (as in Gokan, 2006, and Pintus, 2006), and monetary policy. The economy consists of two types of agents (say, workers and producers), who consume and have perfect foresight during their infinite lifetimes. Workers consume the produced good and supply a variable quantity of labor in each period. Moreover, they face a financial constraint that prevents them from borrowing from their labor income.

On the other hand, producers consume and save in each period, and, most importantly, they are assumed to be more patient than workers (that is, they have a larger discount factor). As a consequence, producers end up holding the entire capital stock (as in Becker, 1980), whereas workers own the whole stock of outside money (which is a dominated asset) at the steady state and nearby. In such a framework, Woodford (1986) has shown that although workers are infinitely long-lived, they behave like two-period living agents. More precisely, workers save their wage income in the form of money today, to be consumed tomorrow. I should emphasize that what I now present is the reduced-form model that is equivalent, near the steady state, to the infinite-horizon setting. (See the appendix.) The reader is referred to Woodford (1986) and Grandmont, Pintus, and de Vilder (1998) for more details on the derivation of this equivalence. In summary, what is key here is that workers are both more impatient and unable to borrow.

A key assumption of the analysis is that a constant flow of public expenditures, $g>0$ in real terms, has to be financed in each period $t \geq 0$. This flow can be interpreted as purchases of the final good produced in the economy, which is in turn obtained by combining labor, $l_{t}>0$, and the capital stock, $k_{t}>0$, resulting from the previous period. The government levies distortionary labor income taxes under a strict rule that imposes a balanced budget. Therefore, the tax rate $0<\tau_{t}<1$ adjusts to meet the constraint that $g=\tau_{t} \omega_{t} l_{t}$ in all periods. For simplicity, I abstract from both capital income taxation (see Judd, 1985, for a justification) and public debt, although results would be similar with fixed government debt and a constant capital tax rate.

Production possibilities are given by CobbDouglas technology, $F\left(k_{t}, l_{t}\right)=k_{t}^{s} l_{t}^{1-s}$. Competitive firms take real rental prices of capital and labor as given and, accordingly, the real wage is $\omega_{t}=$ $\omega\left(k_{t} / l_{t}\right) \equiv(1-s)\left(k_{t} / l_{t}\right)^{s}$; and the real gross return on capital is $R_{t}=R\left(k_{t} / l_{t}\right) \equiv s\left(k_{t} / l_{t}\right)^{s-1}+1-\delta$ in equilibrium, where $0<\delta<1$ is the depreciation rate for capital.

As described in the appendix, the representative, infinitely long-lived worker chooses nextperiod consumption, $C_{t+1}>0$, and labor supply, $l_{t}>0$, so as to maximize $\left\{U\left(c_{t+1}\right)-V\left(l_{t}\right)\right\}$ subject to 


$$
p_{t+1} c_{t+1}=\left(1+\sigma_{t+1}\right)\left(1-\tau_{t}\right) w_{t} l_{t}+p_{t+1} T_{t+1},
$$

where $\sigma_{t+1}>0$ and $T_{t+1}$ represent, respectively, the nominal interest rate on money balances and lump-sum monetary transfers; $p_{t+1}>0$ is the nextperiod price of output (assumed to be perfectly foreseen); and $w_{t}>0$ is the nominal wage (that is, $w_{t}=p_{t} \omega_{t}$ ). The budget constraint in (1) incorporates the fact that workers save in period $t$ their disposable wage income in the form of money, to be consumed in period $t+1$. That is, if $m_{t+1}$ is money demand in period $t$, then the budget constraint in (1) comes from $\left(1-\tau_{t}\right) w_{t} l_{t}=m_{t+1}$ and $p_{t+1} c_{t+1}=\left(1+\sigma_{t+1}\right) m_{t+1}+p_{t+1} T_{t+1}$. The utility functions $U(c)$ and $V(I)$ are increasing, respectively concave and convex. Moreover, consumption and leisure are assumed to be gross substitutes; that is, $U(c)$ is not too concave. The first-order condition of (1) is then $\left[c_{t+1}-T_{t+1}\right] U^{\prime}\left(c_{t+1}\right)=l_{t} V^{\prime}\left(l_{t}\right)$, together with $p_{t+1} C_{t+1}=\left(1+\sigma_{t+1}\right)\left(1-\tau_{t}\right) w_{t} l_{t}+$ $p_{t+1} T_{t+1}$.

Producers do not work, do not hold money, and maximize the discounted sum of utilities derived from the consumption in each period. In period $t$, they consume (and save) part of their capital income, $R_{t} k_{t}$. If the producers' utility function is logarithmic, then their optimal choice simply maintains a constant savings rate; that is, $k_{t+1}=\beta R_{t} k_{t}$, where $0<\beta<1$ is the producers' discount factor (see Woodford, 1986).

Because workers save their wage income in the form of money, the money market equilibrium is

$$
\left(1-\tau_{t}\right) \omega_{t} l_{t}=M_{t+1} / p_{t},
$$

where $M_{t+1}>0$ is money supply. I assume that monetary creation takes the form of both proportional and lump-sum transfers; that is, $M_{t+1}-M_{t}=$ $\sigma_{t} M_{t}+p_{t} T_{t}$.

How does monetary policy then affect the competitive equilibrium of such an economy? The next step in the analysis is to contrast two different types of monetary policies. I call "passive" a rule that keeps the money supply growing at a constant rate and that uses only proportional transfers (that is, $T_{t}=0$ ) in all periods. It is passive in the sense that it does not respond to the state of the economy. In contrast, "active" monetary rules allow the rate of money creation to depend on the state of the economy and may lead to different dynamics, as I now show. More precisely, the two policies are as follows: A passive policy is such that $\sigma_{t}=\sigma$ is constant and $T_{t}=0$, whereas an active policy sets $M_{t}=M$ constant and chooses a sequence for $\sigma_{t}$ and $T_{t}=-\sigma_{t} M / p_{t}$.

Note that the above terminology differs somewhat from Leeper's (1991) definition of passive/ active monetary policy, which is helpful to describe an economy hit by exogenous shocks. In particular, all the rules that I examine here do not depend in an explicit way on either past or expected inflation rates. Consequently, one would label them as passive according to the usage that is most common in the literature.

\section{ESCAPING LAFFER TRAPS THROUGH MONETARY POLICY RULES}

\section{Passive Monetary Rules}

Suppose first that monetary authorities commit to constant money growth and use proportional transfers only. In other words, $\sigma_{t}=\sigma$ and $T_{t}=0$ in all periods. When $\sigma$ is small, one may interpret this rule as resulting from high aversion to inflation. Using the budget constraint (1) and the money market equilibrium (2) with $T_{t}=0$, $M_{t+1} / M_{t}=(1+\sigma)\left(1-\tau_{t}\right) \omega_{t} l_{t} / c_{t}$. If monetary authorities fix the growth rate of the money supply at $1+\sigma=M_{t+1} / M_{t}$ (by controlling the nominal interest rate on money holdings), then $c_{t}=\left(1-\tau_{t}\right) \omega_{t} l_{t}$. Moreover, by defining $u(c) \equiv c U^{\prime}(c), v(l) \equiv l V^{\prime}(l)$, and $\gamma(l) \equiv u^{-1}[v(l)]$, the first-order condition $c_{t+1} U^{\prime}\left(c_{t+1}\right)=l_{t} V^{\prime}\left(l_{t}\right)$ can conveniently be written as $c_{t+1}=\gamma\left(l_{t}\right)$, where $\gamma(I)$ is increasing and convex. Therefore, workers' first-order condition is, in equilibrium, described by $\left(1-\tau_{t+1}\right) \omega_{t+1} l_{t+1}=\gamma\left(l_{t}\right)$ or, given that $g=\tau_{t+1} \omega_{t+1} l_{t+1}$, described by $\omega_{t+1} l_{t+1}=$ $\gamma\left(l_{t}\right)+g$. Then, from the above equilibrium conditions, one easily deduces that all variables are known once the pair $\left(l_{t}, k_{t}\right)$ and $g$ are given. Note, however, that $\sigma$ does not affect the dynamics: That is, predetermined proportional transfers are neutral (see Grandmont, 1986). This implies that intertemporal equilibria may be summarized by 


\section{Figure 1}

\section{Two Pareto-Ranked Steady States When Monetary Policy Is Passive}

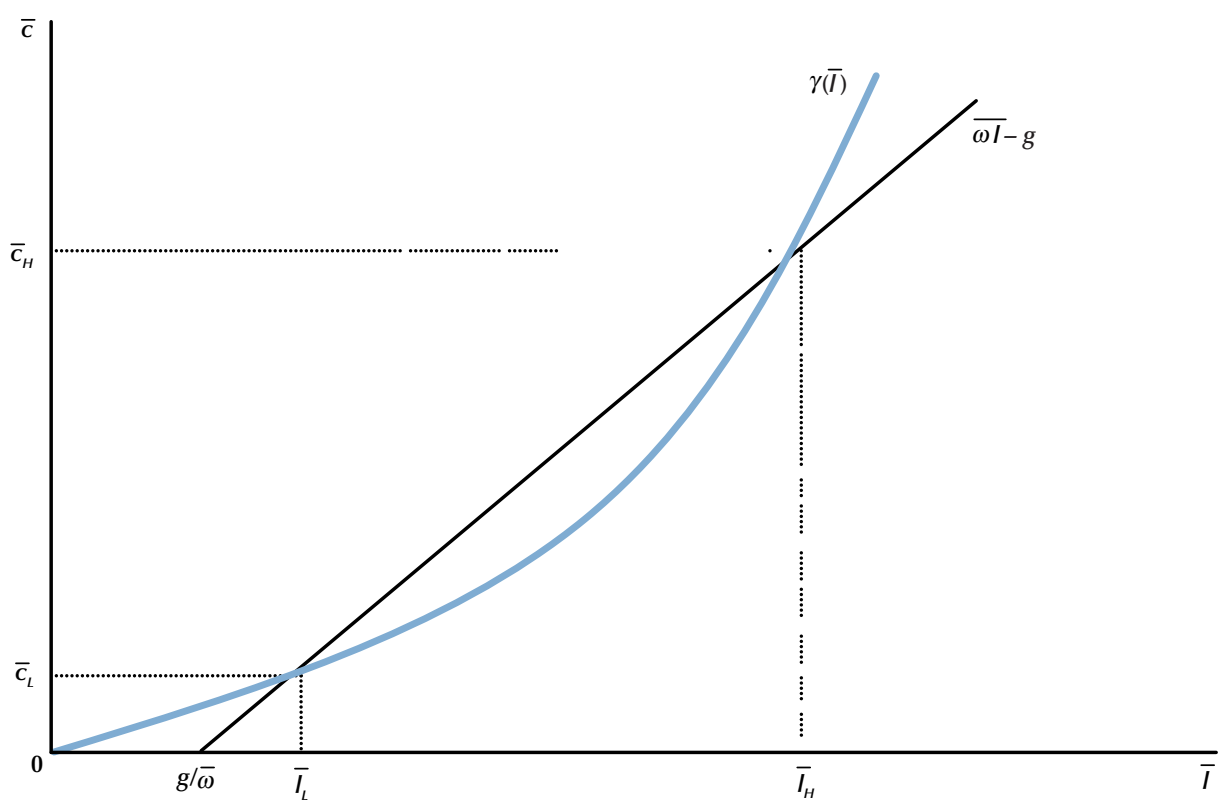

the dynamic behavior of both labor hours (which is a jump variable) and the (predetermined) capital stock, once fiscal policy is announced. In summary, an intertemporal, competitive equilibrium with perfect foresight is a sequence of positive numbers $\left(l_{t}, k_{t}\right)$ for every period $t \geq 0$ such that, given government spending $g>0$ and the initial capital stock $k_{0}>0$,

$$
\left\{\begin{array}{ccc}
\omega\left(k_{t+1} / l_{t+1}\right) l_{t+1} & =\gamma\left(l_{t}\right)+g, \\
k_{t+1} & =\beta R\left(k_{t} / l_{t}\right) k_{t},
\end{array}\right.
$$

where the equations in (3) are to be remembered as the first-order conditions of, respectively, workers and producers.

It is then not difficult to derive the conditions that any steady state must satisfy. From the second equality in (3), the stationary capital-labor ratio, $\bar{k} / \bar{l}>0$, is determined by $R(\bar{k} / \bar{l})=1 / \beta$, which has a unique solution under the assumption of CobbDouglas technology. Note that $\bar{k} / \bar{l}$ is determined by both technology and producers' patience, but it is independent of fiscal and monetary policies.
Moreover, steady-state labor, $\bar{l}$, solves $\bar{\omega} \bar{l}=\gamma(\bar{l})$ $+g$, where $\bar{\omega} \equiv \omega(\bar{k} / \bar{l})$, in view of the first condition in (3). It is straightforward to show that the latter equality — which determines steady-state labor, capital, and output-has two solutions, $\bar{l}_{L}>0$ and $\bar{l}_{H}>\bar{l}_{L}$ as depicted in Figure 1, provided that government spending is not too large.

As shown in Pintus (2006), the two steady states are in fact Pareto-ranked. In essence, the higher steady state produces larger income for both types of agents. The corresponding tax rates are such that $\tau_{L} \equiv g /\left(\bar{\omega}_{L}\right)>\tau_{H} \equiv g /\left(\bar{\omega}_{H}\right)$. Moreover, $\tau_{L}\left(\tau_{H}\right)$ is higher (lower) than the tax rate that maximizes fiscal revenues (that is, the Laffer maximal tax rate). Let us focus on parameter values such that, after linearizing (3) at steady states, the lowest steady state is indeterminate while the highest one is a saddle, as pictured in Figure 2. (See also Gokan, 2006.) In view of the fact that (3) represents the dynamics of the original economy populated by heterogenous, infinitely long-lived agents only near steady states, I now focus on parameter configurations such that both steady 
Figure 2

\section{The Low Steady State (the Laffer Trap) Is Indeterminate and the High Steady State Is a Saddle When Monetary Policy Is Passive}

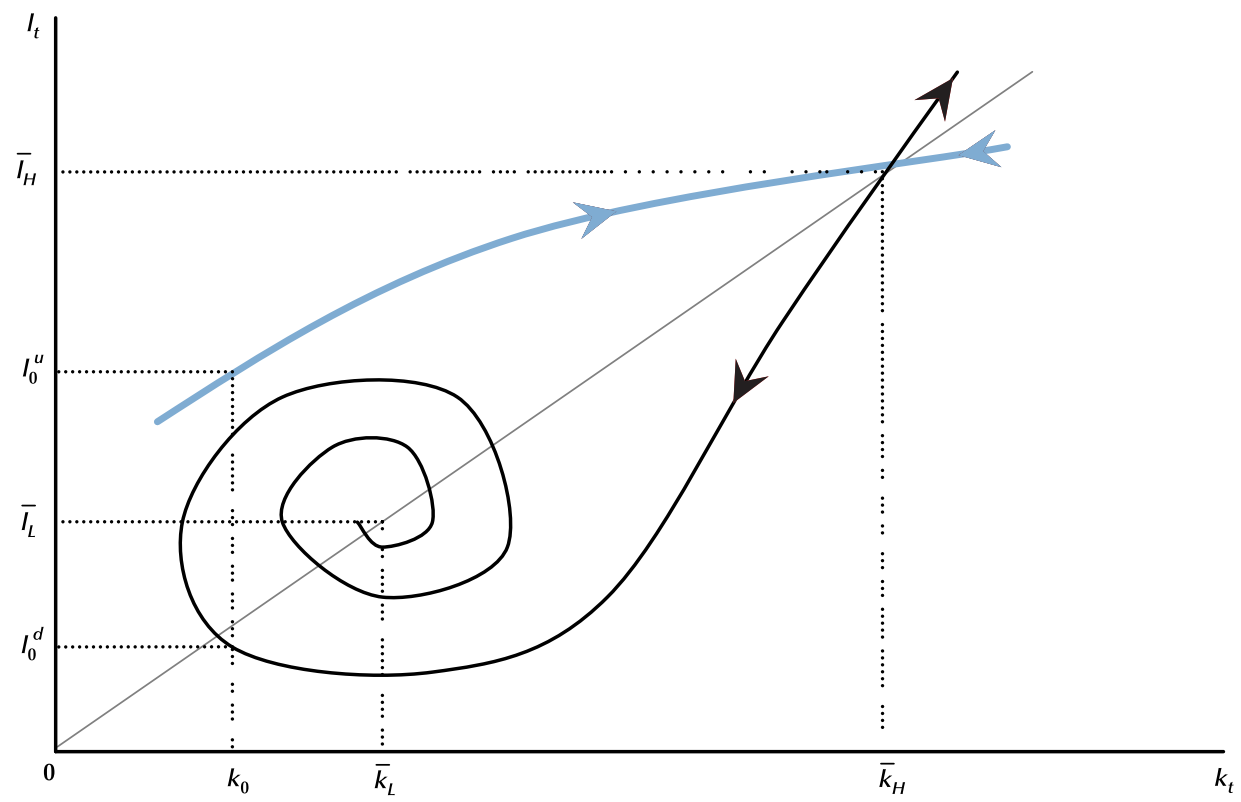

states are "close"; that is, they belong to a small neighborhood. Such cases are shown to arise when parameter values approach some bifurcation levels. (See Pintus, 2006, for details.)

In Figure 2, consider an initial capital stock, $k_{0}>0$, that is close enough to the low steady state, $\bar{k}_{L}$. Then there is a continuum, $\left[l_{0}^{d}, l_{0}^{u}\right]$, of values for labor such that the economy converges to steady state. In period 0 , if labor supply $l_{0}$ happens to be equal to the highest value, $l_{0}^{u}$, then convergence to the high-welfare steady state is ensured. However, if today's labor supply is below the level $l_{0}^{u}$ and larger than some $l_{0}^{d}$, then the economy falls into the Laffer trap. In other words, infinitely many values of labor supply are consistent, in period 0 , with convergence to some steady state. Similarly, if $k_{0}$ is close to (but lower than) $\bar{k}_{H}$, the economy may end up converging either to the high steady state or to the Laffer trap. There is indeterminacy.

In summary, suppose that government spending, $g$, is not too large and that money growth is constant in all periods. Then the economy described in (3) has two steady states: $\left(\bar{l}_{H}, \bar{k}_{H}\right)$ and $\left(\bar{I}_{L}, \bar{k}_{L}\right)$, with $\bar{l}_{H}>\bar{I}_{L}$ and $\bar{k}_{H}>\bar{k}_{L}$ (see Figure 1 ), such that both workers and producers strongly prefer $\left(\bar{l}_{H}, \bar{k}_{H}\right)$. The low steady state $\left(\bar{l}_{L}, \bar{k}_{L}\right)$ (the "Laffer trap") is associated with a tax rate that is higher than the Laffer maximum, whereas $\left(\bar{l}_{H}, \bar{k}_{H}\right)$ is associated with a tax rate that is lower than the Laffer maximum. Moreover, $\left(\bar{l}_{H}, \bar{k}_{H}\right)$ is a saddle, whereas $\left(\bar{l}_{L}, \bar{k}_{L}\right)$ is indeterminate and subject to expectation-driven business cycles (see Figure 2). Therefore, the economy may occasionally switch, because of self-fulfilling expectations, from the neighborhood of the Laffer trap to the saddle-path leading to the high-welfare steady state.

The configuration that appears in Figure 2 turns out to be plausible, as it arises when government spending is (arbitrarily) small, in contrast with findings in Schmitt-Grohé and Uribe (1997). In their analysis, the steady state is unique and is associated, when indeterminate, with a (large enough) tax rate that is lower than the Laffer maxi- 
mum. In contrast, my result shows that indeterminacy and belief-driven business cycles arise because there exists a low, Pareto-dominated steady state, where the tax rate is higher than the Laffer maximum. This is reminiscent of earlier results obtained by Sargent and Wallace (1981) in a monetary economy without capital. The existence of such a Laffer trap calls, in the setting of this article, for a Pareto-improving, active monetary policy that is assumed away in the non-monetary economy of Schmitt-Grohé and Uribe (1997).

Most importantly, regime switching occurs in Figure 2, when the economy abruptly jumps between paths converging monotonically toward the high steady state and volatile paths around the low steady state. The main mechanism giving rise to indeterminacy is that households supply labor today according to their expectations about the inflation rate. More precisely, labor supply is higher (lower) when expected inflation is lower (higher). Therefore, waves of optimism or pessimism turn out to be self-confirming and the economy experiences excess volatility in the absence of any shocks to "fundamentals." The assumption of predetermined public spending is as important here as it is in Schmitt-Grohé and Uribe (1997): This amounts to imposing a fixed cost on the economy, thereby creating a mechanism that is likely to lead, in a similar fashion as increasing returns do, to multiple equilibria and indeterminacy. In that respect, adding government debt to the model would not change the results, as long as the tax rate adjusts to balance the fiscal budget.

The multiplicity of steady states turns out to be robust also with respect to the introduction of lump-sum monetary transfers. Assume instead that money is held constant over time $\left(M_{t}=M\right)$; that is, $T_{t}=-\sigma_{t} M_{t} / p_{t}$. Then the first-order condition of the workers becomes $(1+\sigma) C_{t+1} U^{\prime}\left(C_{t+1}\right)=$ $l_{t} V^{\prime}\left(l_{t}\right)$. Consequently, increasing (decreasing) the rate of money transfer $\sigma$ shifts down (up) the $\gamma(\bar{l})$ locus in Figure 1, which cannot rule out the Laffer trap.

\section{Active Monetary Rules}

The main point of this article is to argue that an active monetary policy may rule out the Laffer trap equilibrium that is associated with active fiscal policy when that fiscal policy operates under a strict balanced budget requirement. One may think about this second policy regime as motivated by inflation targeting, which is designed to avoid large fluctuations of the inflation rate associated with indeterminacy. As illustrated in Figure 2, fluctuations between paths converging monotonically toward the high steady-state and volatile paths around the Laffer trap are associated with large swings in the inflation rate. This is because the inflation rate, given by

$$
\begin{aligned}
& p_{t+1} / p_{t}-1= \\
& {\left[(1+\sigma)\left(\omega_{t} l_{t}-\omega_{t+1} l_{t+1}\right)-\sigma g\right] /\left(\omega_{t+1} l_{t+1}-g\right),}
\end{aligned}
$$

moves together with $l_{t}$ and $k_{t}$ in the above case with passive monetary policy.

Alternatively, one may interpret this regime as originated by a max-min criterion that guides monetary policy and that aims at ruling out the "bad" equilibrium. The idea here is that monetary authorities are concerned about a "worst-case scenario" in which the economy would wander around a low-welfare steady state. In other words, monetary policy tries to avoid the low equilibrium because it is Pareto-dominated in terms of both welfare level and welfare volatility.

As an example of such rules, set $1+\sigma_{t+1}=$ $v\left(l_{t}\right) / u\left(A \psi\left(l_{t}\right)\right)$ and $T_{t}=-\sigma_{t} M_{t} / p_{t}$. Then workers' first-order condition becomes $\left(1+\sigma_{t+1}\right) u\left(c_{t+1}\right)=$ $v\left(l_{t}\right)$ or $C_{t+1}=A \psi\left(l_{t}\right)$. Figure 3 depicts a case such that $A \psi(l)$ is increasing and convex, with $A \psi(l)>0$ only when $l>\underline{l}$, for some $\underline{l}>g / \bar{\omega}$. In addition, the scaling factor $A$ should be appropriately chosen so that the high equilibrium is the unique steady state (see Figure 3). Then intertemporal equilibria are now given by

$$
\left\{\begin{array}{cl}
\omega\left(k_{t+1} / l_{t+1}\right) l_{t+1} & =A \psi\left(l_{t}\right)+g, \\
k_{t+1} & =\beta R\left(k_{t} / l_{t}\right) k_{t} ;
\end{array}\right.
$$

and it is readily shown, by linearizing (4), that the unique steady state remains a saddle point under such a rule. In other words, suppose that government spending, $g$, is not too large and that the rate of proportional monetary transfers, $\sigma_{t}$, follows a rule such that $\sigma_{t+1}=\phi\left(l_{t}\right)$ in all periods. Then there exists a monetary policy rule $\phi(\cdot)$ such 
Figure 3

\section{The Unique (High Welfare) Steady State with Active Monetary Policy}

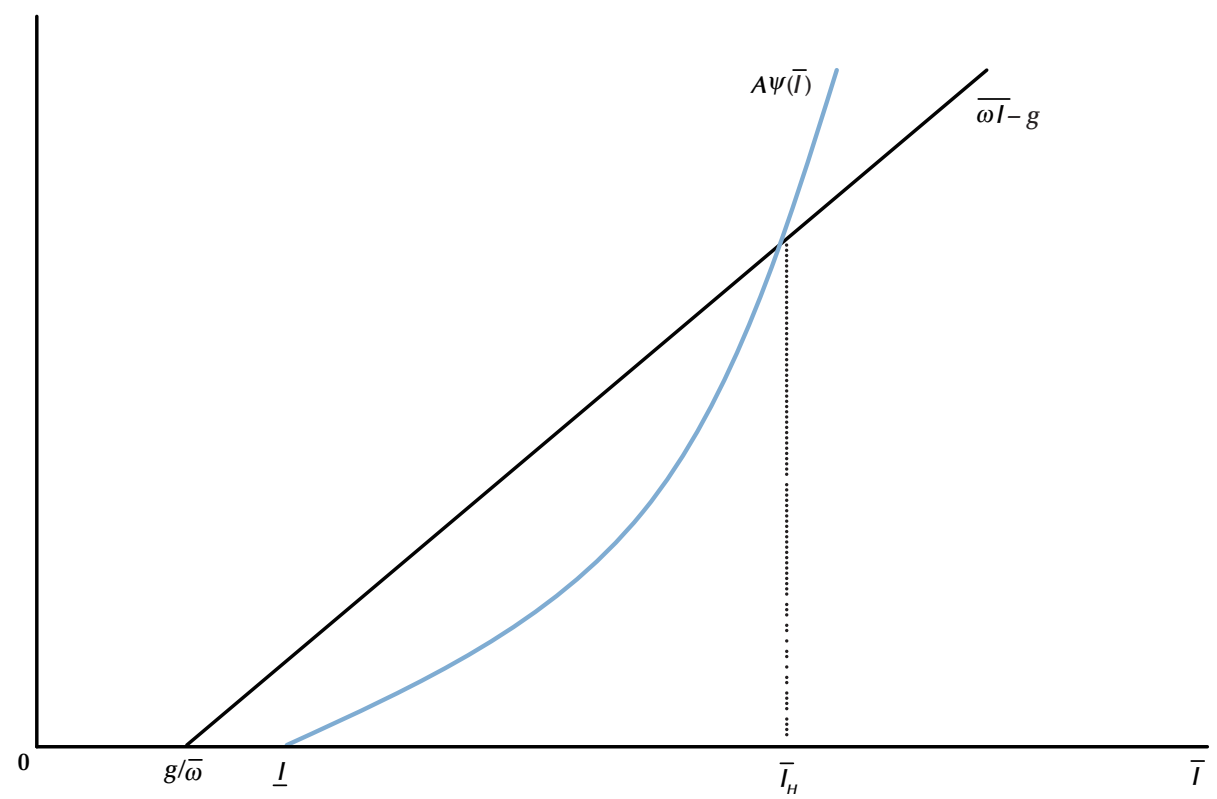

that the economy described in (3) has a unique, saddle-point steady state $\left(\bar{l}_{H}, \bar{k}_{H}\right)$. In other words, such a monetary policy rules out expectationdriven business cycles and implies saddle-path convergence to the Pareto-dominating steady state. Note that both money creation and inflation vanish at steady state; that is, $\sigma$ tends toward zero along the transition to steady state.

Obviously, one may interpret more generally the above rules as relating the nominal interest rate to output, rather than labor, given the capital stock in the current period. In that case, money creation in period $t+1$ is made an increasing function of period- $t$ output. The main intuition here is that when the nominal interest rate is announced to be an increasing function of output, this neutralizes self-confirming expectations about the inflation rate.

\section{CONCLUSION}

If fiscal policy is constrained by a strict balanced-budget requirement, a Laffer trap equi- librium coexists with a Pareto-dominating steady state. The Laffer trap equilibrium features a higher tax rate, lower and volatile macroeconomic variables, and hence lower welfare. Its mere existence makes regime switching possible, when monetary policy is passive, because the economy may abruptly jump from the saddle-path converging toward the high-welfare steady state to volatile paths around the low-welfare steady state. Such a pattern is associated with large swings in the inflation rate. The analysis of this article suggests that one way to push the economy toward the "good" steady state is to abandon passive monetary policies and adopt instead an active monetary rule. Such an active rule may take the form of a commitment to link in a positive fashion the nominal interest rate and the level of aggregate output. Under this commitment, welfare is higher in every period and expectation-driven business cycles are ruled out.

Directions for future research would be to consider, in a more systematic way, the effect of fiscal rules that aim at both redistributing income 
and stabilizing the economy, building on recent contributions by Christiano and Harrison (1999), Guo and Harrison (2001), Aloi, Lloyd-Braga, and Whitta-Jacobsen (2003), and Dupor (2005), among many others. This is most important in view of the fact that the existing results, taken together, are rather inconclusive and suggest that the cyclicality of government expenditures and taxes may or may not stabilize the economy, depending on the precise framework. The relevance of such a question for actual policy also originates from the available data, which show that the level of fiscal cyclicality varies much across OECD countries, as documented by Lane (2003), for instance. This article suggests that when it comes to assessing the impact of active fiscal policies, it is important to understand how they interact with independent monetary policies that may be active or passive.

\section{REFERENCES}

Alesina, Alberto and Rodrik, Dani. "Distributive Politics and Economic Growth." Quarterly Journal of Economics, May 1994, 109(2), pp. 465-90.

Aloi, Marta; Lloyd-Braga, Teresa and Whitta-Jacobsen, Hans Jorgen. "Endogenous Business Cycles and Systematic Stabilization Policy.” International Economic Review, August 2003, 44(3), pp. 895-915.

Antinolfi, Gaetano; Azariadis, Costas and Bullard, James B. "Monetary Policy as Equilibrium Selection." Federal Reserve Bank of St. Louis Review, July/August 2007, 89(4), pp. 331-41.

Becker, Robert A. "On the Long-run Steady State in a Simple Dynamic Model of Equilibrium with Heterogeneous Households." Quarterly Journal of Economics, September 1980, 95(2), pp. 375-82.

Christiano, Lawrence J. and Harrison, Sharon G. "Chaos, Sunspots and Automatic Stabilizers." Journal of Monetary Economics, August 1999, 44(1), pp. 3-31.

Dupor, Bill. "Keynesian Conundrum: Multiplicity and Time Consistent Stabilization." Review of Economic Dynamics, January 2005, 8(1), pp. 154-77.
Gokan, Yoichi. "Dynamic Effects of Government Expenditure in a Finance Constrained Economy." Journal of Economic Theory, March 2006, 127(1), pp. 323-33.

Grandmont, Jean-Michel. "Stabilizing Competitive Business Cycles." Journal of Economic Theory, October 1986, 40(1), pp. 57-76.

Grandmont, Jean-Michel; Pintus, Patrick A. and de Vilder, Robin G. "Capital-Labor Substitution and Competitive Nonlinear Endogenous Business Cycles.” Journal of Economic Theory, May 1998, 80(1), pp. 14-59.

Guo, Jang-Ting and Harrison, Sharon G. "Tax Policy and Stability in a Model with Sector-Specific Externalities." Review of Economic Dynamics, January 2001, 4(1), pp. 75-89.

Judd, Kenneth L. "Redistributive Taxation in a Simple Perfect Foresight Model." Journal of Public Economics, October 1985, 28(1), pp. 59-83.

Kemp, Murray C.; Van Long, Ngo and Shimomura, Koji. "Cyclical and Noncyclical Redistributive Taxation." International Economic Review, May 1993, 34(2), pp. 415-29.

Lane, Philip R. "The Cyclical Behaviour of Fiscal Policy: Evidence from the OECD." Journal of Public Economics, December 2003, 87(12), pp. 2661-75.

Lansing, Kevin J. “Optimal Redistributive Capital Taxation in a Neoclassical Growth Model." Journal of Public Economics, September 1999, 73(3), pp. 423-53.

Leeper, Eric. "Equilibria Under 'Active' and 'Passive' Monetary and Fiscal Policies." Journal of Monetary Economics, February 1991, 27(1), pp. 129-47.

Pintus, Patrick A. "Escaping Laffer Traps." Unpublished manuscript, GREQAM, December 2006.

Sargent, Thomas J. and Wallace, Neil. "Some Unpleasant Monetarist Arithmetic.” Federal Reserve Bank of Minneapolis Quarterly Review, Fall 1981, 5(3), pp. 1-17. 


\section{Pintus}

Schmitt-Grohé, Stephanie and Uribe, Martin.

"Balanced-Budget Rules, Distortionary Taxes, and

Aggregate Instability." Journal of Political Economy,

October 1997, 105(5), pp. 976-1000.
Woodford, Michael. "Stationary Sunspot Equilibria in a Finance Constrained Economy." Journal of Economic Theory, October 1986, 40(1), pp. 128-37.

\section{APPENDIX}

In this appendix, I derive the condition under which the decision of workers reduces to a two-period problem. Workers' intertemporal utility is

$$
\sum_{t=1}^{+\infty} \alpha^{t-1}\left[U\left(c_{t}\right)-\alpha V\left(l_{t}\right)\right]
$$

where $0<\alpha<1$ is their discount factor. Workers face the usual budget constraint

$$
\left(1+\sigma_{t}\right) m_{t}+p_{t} T_{t}+p_{t} R_{t} k_{t}+\left(1-\tau_{t}\right) w_{t} l_{t}=p_{t} c_{t}+p_{t} k_{t+1}+m_{t+1} .
$$

In addition, they cannot borrow and face an intratemporal liquidity constraint such that

$$
\left(1+\sigma_{t}\right) m_{t}+p_{t} T_{t}+p_{t} R_{t} k_{t} \geq p_{t} c_{t}+p_{t} k_{t+1} .
$$

It is not difficult to verify, by manipulating the first-order conditions, that workers do not hold capital (that is, $k_{t}=0$ ) at all dates if

$$
U^{\prime}\left(c_{t}\right)>\alpha R_{t+1} U^{\prime}\left(c_{t+1}\right) .
$$

As the liquidity constraint (7) binds at steady states, condition (8) implies the following: Workers spend their money holdings, i.e., $p_{t} c_{t}=\left(1+\sigma_{t}\right) m_{t}+p_{t} T_{t}$, and save their wage income in the form of money, i.e., $\left(1-\tau_{t}\right) w_{t} l_{t}=m_{t+1}$, to be consumed tomorrow. Under (8), therefore, workers choose $l_{t}$ and $c_{t+1}$ so as to maximize

$$
\left\{U\left(c_{t}\right)-V\left(l_{t}\right)\right\} \text { s.t. } p_{t+1} c_{t+1}=\left(1+\sigma_{t+1}\right)\left(1-\tau_{t}\right) w_{t} l_{t}+p_{t+1} T_{t+1},
$$

as described in the text. Finally, under the assumption that producers discount the future less heavily than workers (that is, $\alpha<\beta<1$ ), condition (8) is met at steady states and nearby: $1>\alpha R(\bar{k} / \bar{l}$ ) because the steady-state return on capital is given by $R(\bar{k} / \bar{l})=1 / \beta$. 